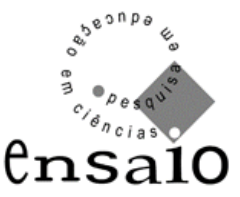

\title{
O ESTUDO DAS VOZES DE ALUNOS QUANDO ESTÃO ENVOLVIDOS EM ATIVIDADES DE INVESTIGAÇÃO EM AULAS DE FÍSICA
}

\section{THE STUDY OF THE STUDENTS VOICES WHEN ARE INVOLVED IN INQUIRES ACTIVITIES IN PHYSICS CLASSES}

\author{
Ana Paula Bossler* \\ Mónica Baptista \\ Ana Maria Viegas Freire ${ }^{* *}$ \\ Silvania Sousa do Nascimento ${ }^{* * * *}$
}

\section{Resumo}

Este artigo busca conhecer, a partir do estudo das vozes, a percepção de alunos sobre o ensino não tradicional quando estão envolvidos em investigações científicas na sala de aula. Para a análise do discurso, o estudo das vozes constitui uma das dimensões investigativas possíveis e corresponde ao “dialogismo” de Bakhtin (1986), princípio segundo o qual nós sempre falamos com as palavras dos outros. A fala de um único sujeito constitui-se das muitas vozes convocadas por ele para compor o discurso. $\mathrm{Na}$ transcrição das entrevistas feitas com 27 alunos, encontramos seis vozes que evidenciam o que pensam os alunos sobre a inovação pedagógica a qual foram submetidos.

Palavras-chave: Ensino de ciências. Investigações científicas. Análise do discurso.

\begin{abstract}
* Doutoranda da Faculdade de Educação, Universidade Federal de Minas Gerais, em estágio na Universidade de Lisboa - paula.bossler@terra.com.br ** Doutoranda de Educacãão, Centro de Investigação em Educação, Faculdade de Ciências, Universidade
de Lisboa - mlmbaptista@gmail.com

*** Professora Doutora, Centro de Investigação em Educação, Faculdade de Ciências, Universidade de Lisboa - afreire@fc.ul.pt

**** Professora Doutora Faculdade de Educação, Universidade Federal de Minas Gerais silnascimento@ufmg.br
\end{abstract}




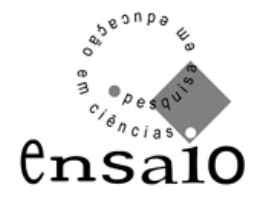

This article sought to know from the study of the voices, the pupils' perception about teaching non-traditional when they are involved in scientific inquiry in the classroom. For discourse analysis, the study of the voices is one of the dimensions and possible investigative corresponds to the "dialogism" of Bakhtin (1986), the principle that we always speak the words of others. The speech of a single subject is made up of many voices called for him to compose the speech. In transcripts of interviews with 27 pupils, we found six voices that show what pupils think about the pedagogical innovation which have been submitted.

Keywords: Science education. Scientific inquiry. Discourse analysis.

\section{INTRODUÇÃO}

A ação desenvolvida na sala de aula é sem dúvida de natureza comunicativa. $\mathrm{O}$ processo de análise do discurso nos possibilita interrogar os sentidos estabelecidos nas muitas formas de comunicabilidade de sala de aula. Para compreendermos os sentidos do texto ou os efeitos de sentido do discurso nele inscritos buscamos ir além da dimensão lingüística da palavra, visto que a relação entre as significações de um texto e o contexto sócio-histórico é constitutivo das próprias significações. Nesse sentido, a perspectiva discursiva pode vir a constituir cenário interpretativo para investigação na prática no ensino de ciências. Para o educador, é de grande interesse conhecer os significados possíveis do discurso produzido em diferentes contextos de produção discursiva do qual a escola é cenário.

O estudo das vozes constitui uma das dimensões investigativa para a análise do discurso que temos aplicado (BOSSLER, 2009). Esse estudo usa o princípio segundo

o qual nós sempre falamos com as palavras dos outros e remete-nos ao “dialogismo” de Bakhtin (1986). Para Ducrot (1987) a polifonia pode ocorrer tanto no 


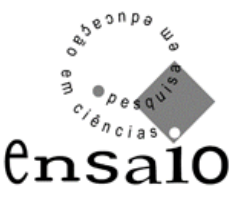

nível do enunciador, quanto do locutor. O sujeito a partir da qual o ponto de vista é apresentado é identificada como o enunciador, e aquela que no enunciado se apresenta como responsável por ele, o locutor. Na voz que aparece no nível da enunciação, o responsável pela idéia expressa não tem suas palavras inscritas no enunciado, mas tem a possibilidade de ver ali materializadas suas opiniões. Então o sujeito da enunciação, não necessariamente é o locutor, mas a voz por ele evocada para destacar um ponto de vista. Já a voz no nível da locução aconteceria quando um sujeito locutor alternaria sua fala com àquela de algum personagem ou de um ausente, multiplicando os locutores em cena. Portanto o indivíduo pode não estar presente no momento em que o discurso se materializa e ser um enunciador, visto que o sujeito que fala pode viabilizar essa presença. Para identificar a presença das vozes, não contamos com marcadores explícitos e analisamos a mise en scène discursiva. As vozes no nível da locução podem ser identificadas graças a mudanças no uso de "tom de voz" e na “velocidade da fala”, e no anúncio explícito no turno de fala que antecede a manifestação, um esclarecimento feito à recepção.

Um único sujeito pode contemplar em sua fala diferentes vozes. Algumas vozes podem ser de antemão esperadas, conhecendo-se a identidade dos enunciadores em cena. Na fala de um Professor, por exemplo, é esperado encontrarmos a Voz do Professor, assim como na fala dos alunos, há a expectativa da presença da Voz do Aluno. Nesse sentido as vozes corresponderiam aos papéis sociais esperados para cada categoria identitária. Além disso, é possível reconhecer outras vozes compondo as falas de cada sujeito aparentemente desvinculadas de seu papel. Nesse sentido, é possível encontrarmos na fala do aluno, além da Voz do Aluno, a Voz dos Pais dos Alunos, a Voz da Adolescência, a Voz da Direção da Escola, etc. As vozes emergem no esforço de análise do pesquisador, que de posse da transcrição, procura enxergar 


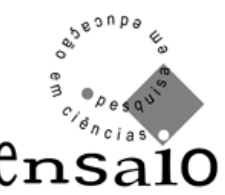

além da identidade declarada do locutor, e se pergunta quem estaria a se expressar ali, a partir das opiniões, idéias e performances presentes. Buscamos, então, no estudo das vozes conhecer aquelas que compõem o repertório de vozes da fala de um determinado sujeito. Assim, entendendo que elas emergem da co-construção de significados entre os sujeitos no contexto de produção discursiva, podemos inferir que a presença ou ausência de determinadas vozes constituem evidências das concepções dos sujeitos acerca dos papéis predeterminados para eles e para os outros sujeitos, interlocutores presentes ou ausentes.

Neste estudo procuramos localizar as vozes nas falas dos alunos envolvidos em situações investigações científicas na sala de aula no contexto da escola portuguesa.

\subsection{Contexto de pesquisa}

Nos últimos 50 anos, os currículos de ciências têm sofrido grandes mudanças como consequência não só da própria evolução da ciência, como também de alterações sociais, culturais, econômicas e políticas (FREIRE, 1993). Também em Portugal, as Orientações Curriculares, do ensino básico ( $7^{\circ}$ ao $9^{\circ}$ ano de escolaridade), para as Ciências Físicas e Naturais, constituem uma resposta para as necessidades de mudança sentidas (GALVÃO et al., 2002). Nelas está explícito a valorização de um ensino centrado nos alunos, fundamentado numa perspectiva construtivista que promova as investigações científicas na sala de aula, a abordagem da Ciência, Tecnologia, Sociedade e Ambiente (CTSA), um ensino orientado para o desenvolvimento de competências e a avaliação como aprendizagem (GALVÃO et al., 2002).

Um currículo orientado para o desenvolvimento de competências requer uma quebra das rotinas por parte do professor assim como dos alunos em sala de aula. Leite (2003) refere que "organizar e desenvolver o currículo, orientando-o para o desenvolvimento de competências pressupõe assumir a responsabilidade de criar situações onde estão presentes as questões pessoais e sociais e em que os alunos e alunas integram e mobilizam as suas experiências” (p.160), tornando-se evidente que a 


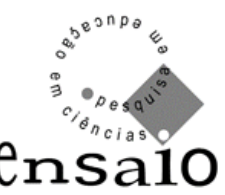

aprendizagem exige o envolvimento cognitivo de cada um que está a aprender. Perrenoud (2001) considera que as competências não se ensinam sendo necessário a criação de condições que potenciem o seu desenvolvimento. Assim, cabe ao professor assumir um novo papel e conceber experiências de aprendizagem que promovam o desenvolvimento de competências que contribuam para a literacia científica (ROLDÃO, 2004).

Hoje em dia, a promoção da literacia científica e a ênfase dada às relações CTSA são conceitos muito invocados e são reconhecidos como uma finalidade educativa (AAAS, 1989; AAAS, 1993; ANDERSON, 2007; BYBEE, 1997; MARTINS, 2003; PALINCSAR; LADEWSKI, 2006; ROBERTS, 2007; VALENTE, 2002). Evidencia-se que a literacia é uma exigência da própria democracia, pois só desta forma serão dadas aos indivíduos ferramentas suficientes para, por exemplo, compreenderem e seguirem debates científicos e discutirem questões tecnológicas. A escola tem a missão de conseguir habilitar os indivíduos para a sua sobrevivência na sociedade, preparando-os não só para a responsabilidade que assumem nesta, como também para o mundo do trabalho. Para Martins (2003), a literacia científica é um conceito que se aplica a cada indivíduo cabendo-lhe, de acordo com o papel que desempenha na sociedade, uma intervenção político-social.

A utilização de investigações nas aulas de ciências é uma estratégia de ensino que permite o desenvolvimento de competências e promove a literacia científica dos alunos (BAPTISTA; FREIRE, 2006; NRC, 1996; WOOLNOUGH, 1998). Com efeito, as investigações envolvem um raciocínio complexo e um elevado empenho por parte dos alunos (TRIGO-TEIXEIRA, 2003) e podem ser exploradas através de questões mais abertas ou mais fechadas, introduzidas por uma questão ou problema para a qual os alunos desconhecem a solução (WOOLNOUGH, 1998).

As investigações científicas na sala de aula, segundo o NRC (2000), são atividades multifacetadas que envolvem: a realização de observações; a colocação de questões; a pesquisa em livros e outras fontes de informação; o planeamento de investigações; a revisão do que já se sabe sobre a experiência; a utilização de ferramentas para analisar e interpretar dados; a exploração, a previsão e a resposta à questão; e a comunicação dos 


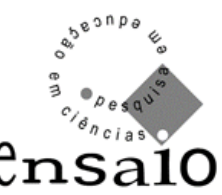

resultados. As atividades de investigação requerem a identificação do problema, usando um pensamento lógico e crítico e considerando explicações alternativas. Com efeito, as investigações envolvem, de uma forma ativa, os alunos na procura do caminho a seguir para encontrar uma ou mais soluções, tratando-se de uma estratégia que tem a potencialidade de promover a compreensão dos fenômenos e o desenvolvimento de outras capacidades. Estas potencialidades permitem dar resposta às exigências do mundo atual (CARLSON; HUMPHREY; REINHARDT, 2003). Segundo Ash e Klein (2000), as investigações na sala de aula são aquelas que envolvem processos de exploração dos materiais e mundo natural. Este processo é conduzido por nós próprios através da curiosidade, do interesse e da perseverança para compreender e resolver um problema. Segundo os autores aprende-se fazendo questões e previsões, formulando hipóteses e criando modelos ou teorias.

De acordo com Ernest (1996), o conceito de investigação é problemático por duas razões. O primeiro problema é que este conceito descreve um processo: a ação de investigar, a procura, exame sistemático, inquirição, pesquisa personalizada e cuidadosa. Em educação essa noção tem sofrido alterações identificando-se a investigação com a questão que constitui o seu ponto de partida. O segundo problema é que se trata de um processo gerador de novas questões o que altera o foco da atividade. Embora as investigações se possam iniciar por uma ou mais questões o objeto da inquirição é alterado por quem conduz a investigação, ao formular novas questões que exigem análise e exploração.

Conceber estratégias de ensino que impliquem que os alunos pensem, pesquisem e selecionem informações, recolham evidências, organizem os argumentos e apresentem as suas conclusões, exigem criatividade e demora algum tempo. É, por isso, necessário persistência da parte do professor, uma vez que é difícil alterar a percepção dos alunos quanto ao seu papel na sala de aula, pois tendem a considerar como lúdicas estas tarefas que envolvem a sua participação ativa e um papel mais passivo do professor, como orientador e moderador e não como transmissor de conhecimentos (OLIVEIRA, 2006). Contudo, uma vez quebrada essa rotina e iniciada outra, centrada nos alunos e levando-os 


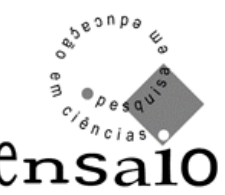

a realizar investigações os alunos não querem retroceder para o ensino tradicional (BAPTISTA; FREIRE, 2006; LOUGHRAN; BERRY; MULHALL, 2006).

Este artigo constitui um excerto de um trabalho de pesquisa mais abrangente que levou professores de Física a quebrarem as suas rotinas, associadas ao ensino tradicional, e a implementarem na sua sala de aula atividades de investigação científica. Após a implementação os seus alunos foram entrevistados para conhecermos o que estes pensam sobre as atividades de investigação propostas para o ensino de uma unidade temática. Nosso objetivo é identificar, na fala dos alunos participantes do estudo quando esses estão envolvidos em investigações científicas na sala de aula, as vozes que evidenciam as suas percepções quanto aos ensinos tradicionais e não-tradicional.

\section{METODOLOGIA}

A metodologia usada neste estudo tem as suas raízes na investigação qualitativa (BOGDAN; BIKLEN, 1994), com orientação interpretativa (ERICKSON, 1986). Uma investigação interpretativa representa uma ferramenta muito importante para examinar o trabalho e o pensamento que os alunos desenvolvem. Essa orientação é construída e não existe apenas uma única interpretação verdadeira, uma vez que existem muitas comunidades interpretativas, cada uma com os seus critérios de avaliação e interpretação (DENZIN; LINCOLN, 1998).

Neste estudo participaram vinte e sete alunos, quinze moças e doze rapazes, pertencentes a uma turma do $8^{\circ}$ ano de escolaridade do Ensino Básico. As suas idades variavam entre os treze (19 alunos) e os quinze anos (2 alunos). A escola a que pertenciam situava-se na região da grande Lisboa.

Os dados desta investigação foram recolhidos através de entrevista em grupo focal (FONTANA; FREY, 1998). As entrevistas em grupo focal são as entrevistas conduzidas em pequenos grupos onde é discutido um determinado tema. Essas entrevistas são desenvolvidas com base em que as pessoas num contexto social aumentam a discussão quando se encontram em grupo. Os participantes constituem um grupo homogêneo, a 


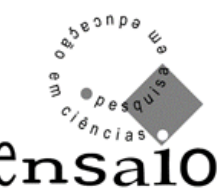

quem se pede que reflitam sobre a questão colocada pelo entrevistador. Os participantes ouvem as respostas de seus colegas e, em seguida, fazem comentários adicionais. Não é necessário que os participantes entrem em desacordo ou cheguem a um consenso (PATTON, 1990). Neste estudo, foram entrevistados 4 grupos de alunos no final da implementação de onze atividades de investigação, cada uma com a duração de 90 minutos. As entrevistas eram compostas por 10 perguntas feitas por um moderador. Selecionamos dentre as questões aquelas que buscavam circunscrever a percepção dos alunos acerca da nova estratégia pedagógica implementada na aula. Portanto, foram analisadas as repostas dadas às seguintes perguntas (transcritas na íntegra do momento da entrevista):

1. Aprenderam mais assim ou no ensino tradicional?

2. O que acharam das atividades?

3. O que gostaram mais? Por que é que gostaram?

4. O que modificariam nas atividades que fizeram?

5. Querem continuar com as atividades?

Para localizarmos as vozes nas falas dos alunos, empreendíamos uma leitura da transcrição buscando identificar possíveis autores para o conteúdo expresso. A natureza das informações disponibilizadas, a performance esperada para determinados sujeitos e eventuais estranhamentos quanto ao percurso discursivo orientaram a localização e a identificação das vozes.

O processo da identificação das vozes trabalha com os conteúdos expressos nas falas dos sujeitos entrevistados, os enunciadores. É possível haver na fala de um sujeito conteúdo expresso que de antemão pertenceriam a outras categorias de sujeitos. Assim, na fala do aluno poderíamos encontrar enunciados cujo conteúdo nos remeteria a performance do professor, o que nos permitiria assumir haver na fala do aluno a voz do professor. O estudo das vozes, ao pressupor a construção dialógica do discurso permite que aventemos antecipadamente as vozes que comporiam determinados contextos discursivos e encontrá-las nas falas dos sujeitos ou não constitui material a ser interpretado pelo pesquisador. 


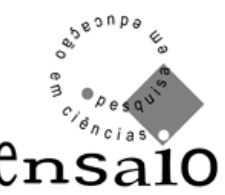

Objetivando explicitar melhor nosso procedimento quanto à identificação das vozes, apresentamos agora como chegamos a Voz do aluno preocupado com a aprendizagem (voz 1), uma das vozes por nós encontrada. No exemplo a seguir (exemplo1), temos um trecho da transcrição da entrevista feita com os alunos. Os nomes atribuídos aos alunos são ficcionais. Nas falas, os alunos descrevem como entendem o processo da aprendizagem para os dois tipos de aula, referindo-se a uma maneira de ensinar.

\section{Exemplo 1}

Pergunta do moderador: O que acharam das atividades?

Júlio - Uma maneira diferente de aprender.

Ricardo - Uma maneira mais fácil de aprender porque ao vermos as coisas a acontecer à nossa frente e com aquilo que a gente faz é mais fácil de aprender.

Júlio - Porque nós temos uma melhor memória fotográfica do que a memória propriamente dita.

Ricardo - A memória para gravar.

Ana - Nas aulas teóricas a gente fica aborrecido mais rápido e a com aulas assim a gente faz as coisas e vimos aquilo o que acontece, interessamo-nos.

Identificamos na fala dos alunos elementos que nos permitem inferir sobre a compreensão dos alunos acerca dos possíveis caminhos para o aprender. Os alunos Júlio e Ricardo estabelecem uma comparação entre as atividades propostas e aquelas com as quais estão familiarizados, ao declararem que as atividades da aula constituem uma maneira diferente de aprender, e é diferente porque é mais fácil. Além disso, os alunos vão além da adjetivação, ao identificarem no processo os elementos que contribuem para que avaliem as aulas assim. As aulas tornam o aprender mais fácil porque permitem que os alunos entrem em contato com a realidade. O conteúdo expresso na fala destes alunos constituem para nós uma voz, a voz pertencente a um aluno genérico e representativo do grupo de alunos ouvidos, que nos conta o que estes sujeitos compreendem do processo do aprender das atividades propostas.

\section{RESULTADOS}




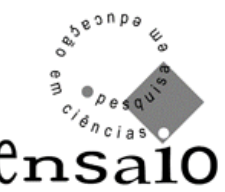

A partir da transcrição das entrevistas localizamos e identificamos sete vozes nas falas dos alunos, que apresentaremos no quadro 1 com suas definições.

\section{Quadro 1: identificação das vozes dos alunos}

\begin{tabular}{|c|c|c|}
\hline Voz do aluno & definição & exemplo \\
\hline $\begin{array}{lll}\text { Preocupado } & \text { com } & \text { a } \\
\text { aprendizagem } & & \end{array}$ & $\begin{array}{l}\text { Declaração de aspectos cognitivos } \\
\text { da atividade }\end{array}$ & $\begin{array}{l}\text { A1 - Uma maneira mais fácil de } \\
\text { aprender porque ao vermos as coisas } \\
\text { a acontecer à nossa frente e com } \\
\text { aquilo que a gente faz é mais fácil } \\
\text { de aprender. }\end{array}$ \\
\hline Preocupado com a nota & $\begin{array}{l}\text { Declaração de aspectos avaliativos } \\
\text { da atividade }\end{array}$ & $\begin{array}{l}\text { A15 - É melhor e assim tira-se } \\
\text { melhores notas. }\end{array}$ \\
\hline Resistente à mudança & Declaração contrária a atividade & $\begin{array}{l}\text { A16 - Eu gostava mais da outra } \\
\text { forma porque me guiava mais pelo } \\
\text { caderno do que pelo livro. E } \\
\text { escrevíamos sempre no caderno. }\end{array}$ \\
\hline Emocionado & $\begin{array}{l}\text { Declaração de aspectos de emoção e } \\
\text { afetividade à atividade }\end{array}$ & A14 - Sim, isto é alegria. \\
\hline Rebelde & Declaração de negação da atividade & $\begin{array}{l}\text { A1 - Enquanto o professor escreve } \\
\text { no quadro estamos entretidos a fazer } \\
\text { outras coisas. }\end{array}$ \\
\hline
\end{tabular}

Das vozes identificadas duas revelaram especificamente as opiniões dos alunos sobre a qualidade do processo de aprendizagem nos modelos de ensino por eles confrontados. A Voz do aluno preocupado com a aprendizagem apareceu em todos os 4 grupos entrevistados, enquanto a Voz preocupado com a nota foi localizada em apenas uma fala de um aluno, o que poderia indicar que os alunos estariam mais preocupados com a aprendizagem do que com as notas que recebem por isso.

A Voz do aluno preocupado com a aprendizagem revela-nos que os alunos entendem que no ensino não-tradicional não só é mais fácil aprender como se aprende mais. Para eles, a aprendizagem ocorre através da pesquisa e do como conseqüência do fazer e do ver na prática os fenômenos acontecerem. Esta voz acredita que o ensino não- 


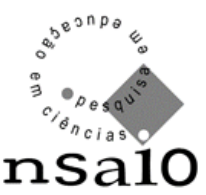

tradicional se configura como uma estratégia inovadora à medida que lhes proporciona mais aprendizagem. É o que podemos observar nos exemplos 2, 3 e 4:

\section{Exemplo 2}

Pergunta do moderador: $\mathrm{O}$ que acharam das atividades?

Ivo - É mais fácil. Porque antes tínhamos que estudar "bué" para um teste e assim nós estamos a aprender a fazer.

\section{Exemplo 3}

Pergunta do moderador: O que acharam das atividades?

Ricardo - Uma maneira mais fácil de aprender porque ao vermos as coisas a acontecer à nossa frente e com aquilo que a gente faz é mais fácil de aprender.

\section{Exemplo 4}

Pergunta do moderador: Aprenderam mais assim ou no ensino tradicional?

Márcio - Conclusão assim aprendemos mais, é um método inovador.

Ana - Inovador, inovador

Já a Voz preocupado com a nota aponta o ensino não-tradicional como sendo melhor por permitir que os alunos obtenham notas melhores nas avaliações.

\section{Exemplo 5}

Pergunta do moderador: O que acharam das atividades?

Alda-É melhor e assim tira-se melhores notas.

A Voz de resistência à mudança expressa o desejo de permanência nas práticas pedagógicas tradicionais, visto representarem as dinâmicas escolares que são familiares para os alunos. Contudo, o argumento utilizado para opor-se à mudança poderia ser empregado também a favor da quebra da rotina, como podemos observar no exemplo 6 .

\section{Exemplo 6}

Pergunta do moderador: Aprenderam mais assim ou no ensino tradicional?

Alice - Eu gostava mais da outra forma porque me guiava mais pelo caderno do que pelo livro. E escrevíamos sempre no caderno. 


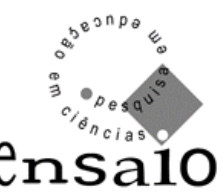

Na fala dos alunos identificamos uma voz, a Voz ligada ao desejo de emoção, que expressa a opinião dos alunos sobre o aspecto da emoção e a afetividade, mesmo que às vezes se aproxime de aspectos lúdico da aula não-tradicional. Ao serem perguntados sobre a natureza das atividades, os alunos declaram que elas eram divertidas, referindo-se às tradicionais como uma “seca” (exemplo 7).

\section{Exemplo 7}

Pergunta do moderador: O que acharam das atividades?

Luiz - Divertidas.

Alberto - Para mim eram fáceis.

Juca - Acho que é uma maneira de nós aprendermos melhor porque nós estamos a fazer as actividades e acabamos por estar mais concentrados.

Manoel - Com as outras aulas é uma seca, a professora a falar, a falar.

Quando perguntados se gostariam de dar continuidade às atividades os alunos confirmam que gostariam e expressam o sentimento com relação às aulas não-tradicionais através do adjetivo “alegria”, como vemos no exemplo 8,a seguir:

\section{Exemplo 8}

Pergunta do moderador: Querem continuar com as atividades?

Todos - Sim.

André - Sim, isto é alegria.

A última voz a apresentarmos revela um comportamento de resistência declarada pelos alunos diante do suposto tédio das aulas tradicionais, como vemos no exemplo 9.

\section{Exemplo 8}

Pergunta do moderador: Aprenderam mais assim ou no ensino tradicional? Ana - Enquanto o professor escreve no quadro estamos entretidos a fazer outras coisas.

Júlio - Eu faço desenhos no caderno. 


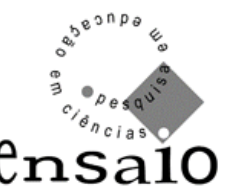

\subsection{Vozes ligadas às percepções de alunos acerca dos ensinos tradicionais e não- tradicional}

A Voz da percepção do ensino tradicional e a Voz da percepção do ensino nãotradicional indicam as concepções dos alunos acerca do modo de ensinar e serão aqui apresentadas em conjunto, visto que muitas vezes ao manifestar-se sobre um tipo de aula o aluno referencia-se ao outro. Estas vozes fornecem subsídios para que possamos reconhecer a concepção do aprendiz sobre os elementos constituintes de uma aula tradicional e as ideias dos alunos sobre a nova estratégia pedagógica a qual foram submetidos. Apresentamos de forma sintética os elementos colhidos que revelam a concepção dos aprendizes sobre a aula tradicional e não-tradicional (Tabela 1):

Tabela 1: Elementos constitutivos dos modelos de aula investigados, de acordo com vozes encontradas nas falas dos alunos

\begin{tabular}{|c|c|}
\hline Ensino tradicional & $\begin{array}{c}\text { Ensino não-tradicional } \\
\text { (investigações científicas) }\end{array}$ \\
\hline $\begin{array}{l}\text { - } \text { Teórico } \\
\text { - A professora é quem fala } \\
\text { - Os alunos apenas ouvem } \\
\text { - Há excesso de } \\
\text { informação } \\
\text { - Só ouvir não desperta o } \\
\text { interesse }\end{array}$ & $\begin{array}{l}\text { - É uma maneira diferente de } \\
\text { aprender } \\
\text { - É mais fácil aprender } \\
\text { - É um “ver acontecer” } \\
\text { - } \text { Desperta o interesse } \\
\text { - Aprende-se por si próprio } \\
\text { - } \quad \text { Aprende-se a pesquisar } \\
\text { - } \quad \text { Pode-se relacionar teoria e } \\
\text { - prática } \\
\text { - } \quad \text { Eode-se fazer experiências } \\
\text { - } \quad \text { O fazer desperta o interesse }\end{array}$ \\
\hline
\end{tabular}

Como podemos observar na tabela 1, o estudo das vozes permite-nos reunir indícios quanto à concepção dos alunos sobre o desenho estratégico das aulas. Os alunos identificam papéis bastante diferentes para o professor e para o aprendiz nos dois tipos de aula. Na aula não-tradicional propiciaria um papel mais ativo do aluno, limitado à escuta nas aulas tradicionais. É o que podemos observar no exemplo 9, que traz a duas vozes na 


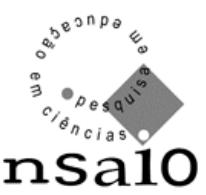

fala dos alunos, contendo evidências dos papéis dos sujeitos. Percebe-se ainda que para os alunos, a aula tradicional corresponderia às aulas teóricas, nas quais o professor seria o protagonista da fala.

\section{Exemplo 10}

Pergunta do moderador: Aprenderam mais assim ou no ensino tradicional?

Ana - Porque na outra entrava muita coisa.

Júlio - E depois era muito mais confuso.

Márcio - Ouvir um professor a falar, a falar não nos interessa minimamente.

Ana - Sim nós pomo-nos a desenhar. As aulas assim ajudaram-me mais do que se fossem teóricas, principalmente na parte dos átomos.

Júlio - A mim também.

Márcio - Numa aula teórica é muito difícil mantermo-nos quietos. Assim, estamos concentrados a aprender coisas. (...)

Podemos observar no exemplo 10 novamente a aula teórica ser associada ao ensino tradicional e em oposição a idéia de dinamismo com a presença dos experimentos nas aulas não-tradicionais.

\section{Exemplo 11}

Pergunta do moderador: Querem continuar com as atividades?

Márcio - Porque é das únicas aulas que a gente tem diferentes das outras. As outras são teóricas, nas outras temos que estar sempre a ouvir o professor.

Ana - Fazemos as experiências.

Júlio - E depois torna mais importante as coisas, com mais interesse.

Se nas aulas teóricas o papel esperado para o aprendiz é o da escuta passiva, no novo modelo os alunos assumem a ação. Além disso, como vemos nos exemplos a seguir (exemplo 12 e 13), o novo papel potencializa a aprendizagem.

\section{Exemplo 12}

Pergunta do moderador: Aprenderam mais assim ou no ensino tradicional? 


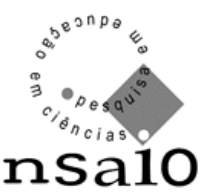

Ivo - Eu prefiro. Assim aprendemos por nós e pesquisamos no livro. Eu já sei pesquisar.

Alda - Aprende-se mais.(...)

\section{Exemplo 13}

Pergunta do moderador: Aprenderam mais assim ou no ensino tradicional?

Márcio - Acho que é uma maneira de nós aprendermos melhor porque nós estamos a fazer as actividades e acabamos por estar mais concentrados.

João - Uma maneira diferente de aprender.

Ricardo - Uma maneira mais fácil de aprender porque ao vermos as coisas a acontecer à nossa frente e com aquilo que a gente faz é mais fácil de aprender.

\section{CONCLUSÕES}

O estudo das vozes permitiu que localizássemos nas entrevistas o conjunto de opiniões dos alunos que revelam as concepções dos aprendizes acerca do ensino nãotradicional em comparação ao tradicional. Nossa amostra constitui fração de uma amostra maior, o que torna nossas considerações por hora apenas apontamentos.

Essa etapa do estudo revelou que os alunos envolvidos na pesquisa integram em suas falas vozes apreciativas de dois modelos pedagógicos. Contudo, os alunos entrevistados revelaram apreciar as estratégias de ensino centradas neles. Contrariamente, as estratégias centradas no professor, como expor a matéria e ditar apontamentos, levam à distração do aluno e não facilitam a aprendizagem. As alterações detetadas colocam os alunos no centro das suas aprendizagens, deixando para trás o ensino tradicional e promovendo um ensino centrado nestes, onde aprendem fazendo e mobilizando os conhecimentos científicos nas diferentes situações vivenciadas, tal como preconizam as Orientações Curriculares (GALVÃO et al., 2002).

As vozes identificadas indicam que a concepção de aula não-tradicional e aula tradicional dos alunos corresponde aqueles descritos pela literatura (CACHAPUZ, 2000). É interessante contudo reunir evidências de que os alunos encontram-se sensíveis às 


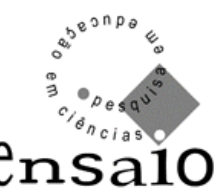

estratégias implementadas ao longo das aulas, estando aptos a emitir opiniões e a argumentar a favor ou contra um determinado modelo.

A Voz do aluno preocupado com a aprendizagem poderia indicar que os alunos entrevistados teriam empreendido um exercício de metacognição, à medida que demonstram refletir sobre sua própria aprendizagem a partir das diferentes nuances da estratégia utilizada.

\section{Referências Bibliográficas}

AMERICAN ASSOCIATION FOR THE ADVANCEMENT OF SCIENCE (1989). Science for all americans. Washington: Author.

AMERICAN ASSOCIATION FOR THE ADVANCEMENT OF SCIENCE (1993). Benchmarks for science literacy. New York: Oxford University Press.

ANDERSON, C. Perspectives on science learning. In ABELL, S. K.; LEDERMAN, N. G. (Eds.). Handbook of research on science education. 1.ed. Mahwah: Lawrence Erlbaum Associates. 2007.

ASH, D.; KLEIN, C. Inquiry in the informal learning environment. In Minstrell, J.; van ZEE, E. H. (Eds.), Inquiry into Inquiry Learning and Teaching in Science. Washington, CA: Corwin. 2000. p.216-240.

BAKHTIN, M. Marxismo e Filosofia da Linguagem. Tradução de Michel Lahud; Yara Frateschi Vieira. São Paulo: Hucitec. 1986.

BAPTISTA, M; FREIRE, A. M. Investigações em aulas de ciências físico-químicas. Mudanças nas percepções de alunos do $8^{\circ}$ ano relativamente ao ensino e à avaliação. Investigar em Educação, v.5, p.237-257. 2006.

BOGDAN, R.; BIKLEN, S. (1991). Investigação qualitativa em educação: Uma introdução à teoria e aos métodos. Porto: Porto. 1994.

BYBEE, R. Achieving scientific literacy. From purposes to practices. Portsmouth, NH: Teachers College. 1997. 


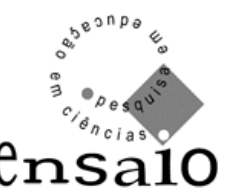

CACHAPUZ, A. Perspectivas de ensino. Textos de apoio, $\mathrm{n}^{0} 1$. Porto: Centro de Estudos de Educação em Ciência. 2000.

CARLSON, L.; HUMPHREY, G.; REINHARDT, K. Weaving science inquiry and continuous assessment. Thousand Oaks, CA: Corwin. 2003.

DENZIN, N. K.; LINCOLN, Y. S. Introduction: Entering the field of qualitative research. In DENZIN, N.; LINCOLN, Y. (Eds.), Collecting and interpreting qualitative materials. Thousand Oaks, CA: Sage. 1998.

DUCROT, O. O dizer e o dito. Campinas: Pontes. 1987.

ERICKSON, F. Qualitative methods in research on teaching. In WITTROCH, M. C. (Ed.), Handbook of research on teaching. New York, NY: Macmillan. 1986. p.119-158.

ERNEST, P. Investigações, resolução de problemas e pedagogia. In ABRANTES, P.; CUNHA LEAL, L.; PONTE, J. P. (Eds.), Investigar para aprender matemática. Lisboa: Projecto matemática para todos e associação de professores de matemática. 1996.

FONTANA, A.; FREY, J. Interviewing: the art of Science. In DENZIN, N.; LINCOLN, $\mathrm{Y}$. (Eds.), Collecting and interpreting qualitative materials. Thousand Oaks, CA: Sage. 1998. p.47-78.

FREIRE, A. M. Um olhar sobre o ensino da Física nos últimos cinquenta anos. Revista de Educação, v.3, n.1, p.37-49. 1993.

GALVÃO, C. et al. Ciências Físicas e Naturais. Orientações Curriculares para o $3^{\circ}$ ciclo do ensino básico. Lisboa: Ministério da Educação, Departamento da Educação Básica. 2002.

LEITE, C. Para uma escola curricularmente inteligente. Porto: Asa. 2003.

LOUGHRAN, J.; BERRY, A.; MULHALL, P. Understanding and developing science teachers. Pedagogical content knowledge. Monash University, Clayton, Austrália: Sense. 2006.

MARTINS, M. I. Literacia científica e contributos do ensino formal para a compreensão pública da ciência. Aveiro: Universidade de Aveiro. 2003. 


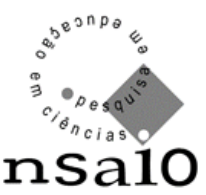

NATIONAL RESEARCH COUNCIL - NRC. Inquiry and the national science education standards. Washington, DC: National Academy. 2000.

NRC (NATIONAL RESEARCH COUNCIL). National science education standards. Washington, DC: National Academic. 1996.

OLIVEIRA, M. Ensinar e Aprender Ciências Naturais, Avaliando: A perspectiva dos Alunos. Tese de mestrado não publicada. Departamento de Educação, Faculdade de Ciências, Universidade de Lisboa, Lisboa. 2006.

PALINCSAR, A.; LADEWSKI, B. Literacy and the learning sciences. In SAWYER, R. (Ed.), The cambridge handbook for the learning sciences $\left(1 .^{a}\right.$ ed.). Cambridge: Cambridge University. 2006.

PATTON, M. Q. Qualitative evaluation and research methods. 2.ed. Newbury Park, CA: Sage. 1990.

PERRENOUD, P. Porquê construir competências a partir da escola? Desenvolvimento da autonomia e luta contra as desigualdades. Porto: ASA. 2001.

ROBERTS, D. Scientific literacy/science literacy. In ABELL, S.; LEDERMAN, N. (Eds.), Handbook of research on science education. 1. ed. Mahwah: Lawrence Erlbaum. 2007.

ROLDÃO, M. C. Gestão do Currículo e avaliação de competências: As questões dos professores. 2.ed. Lisboa: Editorial Presença. 2004.

TRIGO-TEIXEIRA, H. M. M. Trabalho laboratorial de natureza investigativa. Perspectivas de alunos sobre a sua utilização em aulas de Física no ensino secundário. Tese de mestrado não publicada. Faculdade de Ciências da Universidade de Lisboa, Lisboa. 2003.

VALENTE, O. Literacia e educação científica. Actas do Encontro na Universidade de Évora. Évora: Universidade de Évora. 2002.

WOOLNOUGH, B. Authentic Science in schools, to develop personal knowledge. In WELLINGTON, J. (Ed.) Practical work in school science. Which way now? London: Routledge. 1998. p.109-125.

Data de recebimento: 01/02/09 


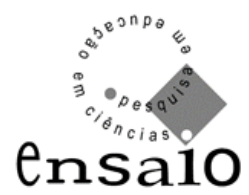

Data de aprovação: 01/09/09

Data de versão final: 16/09/09 